\title{
Spray Dried Amorphous Form of Simvastatin: Preparation and Evaluation of the Buccal Tablet
}

\author{
Nagaraja SreeHarsha, ${ }^{1,3, \star}$, Jagadeesh Gurupadayya Hiremath ${ }^{2}$, Suhas Sarudkar ${ }^{4}$, Mahesh Attimarad $^{1}$, \\ Bandar Al-Dhubiab1, Anroop Balachandran Nair', Katharigatta Narayanaswamy Venugopala ${ }^{1,5}$, \\ Afzal Haq Asif ${ }^{6}$
}

${ }^{1}$ Department of Pharmaceutical Sciences, College of Clinical Pharmacy, King Faisal University, Al-Ahsa, SAUDI ARABIA.

${ }^{2}$ Department of Pharmaceutics, PA College of Pharmacy, Mangalore, Karnataka, INDIA.

${ }^{3}$ Department of Pharmaceutics, Vidya Siri College of Pharmacy, Bangalore, Karnataka, INDIA.

${ }^{4}$ Department of Pharmaceutics, KLE University, Woman's College of Pharmacy, Belgaum, Karnataka, INDIA.

${ }^{5}$ Department of Biotechnology and Food Technology, Durban University of Technology, Durban, SOUTH AFRICA.

${ }^{6}$ Department of Pharmacy Practice, College of Clinical Pharmacy, King Faisal University, SAUDI ARABIA.

\begin{abstract}
Background: The success of a drug primarily depends on its bioavailability. By enhancing the solubility and dissolution properties of drugs that are scarcely water soluble, significantly improves their bioavailability. Methods: This study was aimed to prepare a solid dispersion of the drug simvastatin that is a poorly water-soluble drug, through the spray drying technique. Solid dispersion carrier PVP, adsorbent Aerosil 200 and solvent dichloromethane were used to prepare solid dispersion. The pure simvastatin, solid dispersion and physical mixture were analyzed using FTIR, XRD and DSC studies. IR studies confirmed the possibility of hydrogen bonding in solid dispersion. Results: XRD and DSC studies revealed that the amorphous form of simvastatin was present in the solid dispersion. The spray dried form of simvastatin was formulated into a buccal tablet by using carbopol 934 and HPMC K4M as mucoadhesive polymers. The drug release from buccal tablets indicated that improvement in solubility, the rate of dissolution of poorly water-soluble drug simvastatin. Conclusion: The study shows that the tremendous potential of solid dispersions of simvastatin by using spray drying technique.
\end{abstract}

Key words: Spray drying, Crystalline, Simvastatin, Buccal tablet, Hydroxy propyl methyl cellulose.

\section{INTRODUCTION}

Many drugs have been developed in the pharmaceutical field which intrinsically have low water-solubility. The dissolution rate of a drug has been explained by NoyesWhitney equation, ${ }^{1}$ and is dependent on its solubility and surface area. And it is more suitable to cause increase in the surface area of the drug by the size reduction of its crystals as compared to using other methods to improve the drug solubility. Several methods have been to solve the solubility problem and various pharmaceutical engineering techniques have been used for this purpose, including grinding, ${ }^{2}$ grinding with additive, ${ }^{3}$ inclusion compound with cyclo$\operatorname{dextrin}^{4,5}$ and salt formation. The dissolu- tion rate and the bioavailability of poorly water-soluble drug have been significantly improved by using solid dispersion of drug and it has become a widely used technique. ${ }^{6}$ The properties and features of such solid dispersions of drugs are affected by various factors, such as the preparation method and the type of the carrier used..$^{7-9}$ And the number of water-soluble carrier materials, especially $\mathrm{PEG}^{10}$ or $\mathrm{PVP}^{11}$ have gained attention for this purpose.

One of the most useful techniques in pharmaceutical engineering that are used to make spherical drug crystals which are small in size, uniform and have narrow distribution, is the spray drying technique. This
Submission Date: 14-05-2019; Revision Date: 06-10-2019; Accepted Date: 22-11-2019

DOI: 10.5530/ijper.54.1.6 Correspondence: Dr. SreeHarsha Nagaraja, Department of Pharmaceutical Sciences, College of Clinical Pharmacy, King Faisal University, Al-Ahsa-31982, SAUDI ARABIA.

Phone: +966 6535485322

E-mail: sharsha@kfu.edu.sa

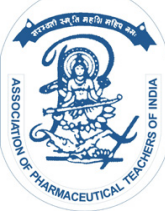

www.ijper.org 
method has an added advantage over other methods, as the granulation and drying of particles is achieved in one single step. The spray drying technique leads to a physical transformation of the drug and forms an amorphous or semi-amorphous phase or semi-crystalline state of the drug. ${ }^{12,13}$ The amorphous phase is a metastable state and quickly revert to the more stable crystalline state. However, it significantly improves the dissolution rate of poorly water-soluble drugs as thermodynamically; it is a high energy state. The combination of the drug with a hydrophilic carrier imparts a high solid-liquid surface tension and forms a micro-environment in which the solubility of the drug is increased. It also prevents agglomeration and aggregation of individual drug particles, both of which can impart water insolubility. ${ }^{14}$ Over the past four decades, many publications have investigated various pharmaceutical aspects of solid dispersions; however, the use of spray drying is only limited to few marketed products. ${ }^{15}$ Major problems which influence the success rate of spray drying technology include: The cost of preparation, difficulties in processing and physical instability of the drug. ${ }^{16-18}$ However, it has been proposed that the mechanical strength and dissolution rate of solid dispersions of drug can undergo changes with time. ${ }^{19}$

In the present investigation, the spray drying technique was applied to poorly water-soluble drug, simvastatin and a hydrophilic polymer Polyvinylpyrrolidone K25 (PVP) was attached to the drug by using a varied combination of Aerosil 200. The FTIR, XRD and DSC studies are performed to study the compatibility of drug and carrier along with the presence of crystallinity and its thermal properties. Initially, the solid dispersions were analyzed by comparing with pure drug and the respective Physical Mixtures (PMs) in the same ratios. The solid dispersions are then formulated into fast dissolving tablets and further subjected to in vitro characterization.

\section{MATERIALS AND METHODS}

\section{Materials}

Simvastatin was generously given by G Amphray Pvt. Ltd. (Mumbai, India). PVP K25 (Sanofi-Aventis), Aerosil 200 (Degussa). The reagents and solvents used were of analytical grade.

\section{Solid Dispersion and Physical Mixture Preparation}

Simvastatin was dissolved in an adequate amount of dichloromethane either alone or with PVP (1:1 part by weight.). A proposed quantity of Aerosil 200 (Table 1) was added slowly to this solution to obtain homogenous suspensions. Next, the spray drying performed using laboratory scale spray dryer (Lab-ultima, Mumbai, India) under following set of conditions: inlet temperature, $350^{\circ} \mathrm{C}$; outlet temperature, $26-280^{\circ} \mathrm{C}$; feed rate, $6-8 \mathrm{ml} / \mathrm{min}$; atomization air pressure, $2 \mathrm{~kg} / \mathrm{cm}^{2}$ and aspiration, $-200 \mathrm{~mm}$. By mixing drug and excipients physically, the mixtures of drugs were prepared and processed for in a mortar for ten minutes to obtain a uniform mixture. Finally, the filtration of the samples was carried out using a fine mesh $(150 \mathrm{~mm})$ and stored in a desiccated place for future use.

\section{Drug content}

Around $10 \mathrm{mg}$ of the solid dispersion of simvastatin was accurately weighed and mixed in an appropriate quantity of methanol. The spectrophotometric analysis was carried out to determine the density or content of the drug, at $238 \mathrm{~nm}$ using UV- spectrophotometer (V-530, JASCO and Japan).

\section{Saturation solubility}

The solubility increase of simvastatin was analyzed by adding different formulations of simvastatin to $10 \mathrm{ml}$ of phosphate buffer ( $\mathrm{pH}$ 6.6). The mixing of samples was carried out on a water bath shaker $\left(250^{\circ} \mathrm{C}\right)$ for two days. Finally, the samples were filtered, diluted and spectrophotometrically analyzed at $238 \mathrm{~nm}$.

\section{FTIR analysis}

The pure drug, pure polymers, physical mixtures and solid dispersions of drug were subjected to infrared spectroscopy (Model-V-5300, JASCO and Japan). For this purpose, the sample preparation was carried out and drug pellets were formed by adding samples in potassium bromide solution and vacuum packed. . The pellets were further analyzed and the spectra scans were taken between 400 to $4000 \mathrm{~cm}^{-1}$ at a resolution of $4 \mathrm{~cm}^{-1}$.

\section{XRD patterns}

The examination of XRD patterns were carried using X-ray diffractometer (PW 3710, Philips analytical B.V.). The drug samples were exposed to monochromatized $\mathrm{Cr} \mathrm{Ka}$ radiation $\left(2.289 \mathrm{~A}^{\circ}\right)$ and analyzed between 10 to $70^{\circ} \mathrm{C} 20$. The voltage was set at $40 \mathrm{kV}$ and the current was set at $25 \mathrm{~mA}$. The XRD analysis of pure drug, polymers and physical mixture was carried out for the evaluation of change in crystalline nature of pure drug by the addition of other polymers.

\section{DSC analysis}

A differential scanning calorimeter equipped with an intracooler (Mettler-Toledo, Switzerland) was used to carry out the DSC studies. And indium/zinc standards 
were used to calibrate the enthalpy and temperature of DSC. The samples (pure drug, pure polymers, the physical mixture of drug and polymers and SDs) were packed in pans and heated at $200^{\circ} \mathrm{C} / \mathrm{min}$ over a temperature range of $20-1500^{\circ} \mathrm{C}$. An inert experimental environment was obtained by using nitrogen gas at a flow rate of $50 \mathrm{ml} / \mathrm{min}$.

\section{Preparation and Evaluation of Fast dissolving tablets}

A direct compression method was used to produce the mucoadhesive bilayer tablets using carbopol 934 and HPMC K4M as mucoadhesive polymers. ${ }^{20,21}$ The backing layer and core layer composition are shown in Table 2. The drug was homogeneously mixed with carbopol 934, HPMC K4M and magnesium stearate in a glass mortar for fifteen minutes to prepare simvastatin (equivalent to $5 \mathrm{mg}$ ) and mucoadhesive polymer mixture (core layer). This mixture $(150 \mathrm{mg})$ was then compressed using $8 \mathrm{~mm}$ stainless steel punch and die in the hydraulic press. By raising the upper punch, the backing layer of EC granules $(50 \mathrm{mg})$ was positioned on the first layer. The two layers were then pressed and the mucoadhesive bilayer tablet was formed. These buccal tablets were assessed for various features, including swelling studies, hardness, thickness, weight variation, surface $\mathrm{pH}$, friability, ex-vivo mucoadhesive ability and in-vitro drug release studies.

\section{Surface $\mathrm{pH}$ determination}

The prepared buccal tablets were analyzed for their surface $\mathrm{pH}$ in order to determine the risks of any associated side effects. It is known that extreme $\mathrm{pH}$, acidic or alkaline, can cause irritation in the oral mucosa. Ideally the surface $\mathrm{pH}$ of any drug should be close to neutral. For this purpose, the surface $\mathrm{pH}$ of the formulation was determined using the method proposed by Bottenberg et al. with some modification. The surface $\mathrm{pH}$ was measured using a glass electrode. The tablets were kept in $1 \mathrm{ml}$ of distilled water $(\mathrm{pH} 6.6 \pm 0.05)$ for $2 \mathrm{~h}$ which allowed them to swell and $\mathrm{pH}$ was measured by bringing the electrode in contact with the drug surface and equilibrated for $1 \mathrm{~min}$.

\section{Swelling studies}

The percentage hydration of the buccal tablets was used as a determinant of their swelling property. For this purpose, each tablet was weighted (W1) and transferred to phosphate buffer $\mathrm{pH}$ 6.6 for a specific period. The tablets were removed and wiped clean by using filter paper and were weighed again (W2). The following formula was used to calculate the percent hydration: ${ }^{20}$

\begin{tabular}{|c|c|c|c|c|}
\hline \multirow{2}{*}{\multicolumn{2}{|c|}{$\begin{array}{c}\text { Formulation } \\
\text { Simvastatin }\end{array}$}} & \multicolumn{3}{|c|}{ Quantity (Parts by weight) } \\
\hline & & \multirow{2}{*}{$\begin{array}{c}\text { PVP } \\
1\end{array}$} & \multirow{2}{*}{$\begin{array}{c}\text { Aerosil } \\
\mathbf{2 0 0} \\
1\end{array}$} & \multirow[b]{2}{*}{-} \\
\hline SD 1:1 & PM 1:1 & & & \\
\hline SD $1: 2: 2$ & PM 1:2:2 & 1 & 2 & 2 \\
\hline SD 1:3:2 & PM 1:3:2 & 1 & 3 & 2 \\
\hline
\end{tabular}

W2-W1

$\%$ hydration $=$

W1

\section{Ex vivo mucoadhesive strength}

The mucoadhesive or bio-adhesive ability of prepared buccal tablets was analyzed using a specialized physical balance and procedure employed by Gupta $e t$ al. For this purpose, a fresh buccal mucosa sample was collected from sheep from a local slaughterhouse (Approved by institutional ethical committee, Dept. of Pharmacology, JNMC, KLE University, Belgaum). The underlying loose tissues and fat were removed to obtain the mucosal membrane. The membrane was then washed with dis. water and phosphate buffer $\mathrm{pH} 6.6$ at $37 \pm 10^{\circ} \mathrm{C}$, in a two-step rinsing method. The buccal mucosa was tied to the petri dish that contained phosphate buffer. The buccal tablet was then attached to the lower side of a thread using cyanoacrylate adhesive. The two sides of the balance were adjusted at an equal position by using five grams weight on the right-hand pan and with a tablet in the left-hand pan. The weight was removed from the right-hand pan, which lowered the tablet over the mucosa and was given a five-minutes contact time. Slowly, the weight was added to the right-hand pan until the tablet separated from the surface of mucosa. ${ }^{21}$

\section{Disintegration test}

Each mucoadhesive buccal tablet was analyzed for its dissolution ability using a simple disintegration test. It was performed by immersing the tablet in a glass petri plate with water (20 to $25 \mathrm{ml}$ at room temperature, $37 \pm$ $10^{\circ} \mathrm{C}$ ). The buccal tablets were observed for any kind of morphological changes. ${ }^{22}$

\section{In vitro drug release studies}

The analysis of in vitro drug release ability of both spray dried simvastatin buccal tablet, as well as pure simvastatin buccal tablet, was performed. The United States Pharmacopoeia (USP) XXIII rotating paddle method was used to analyze the release rate of the drug from the bilayer tablets. The dissolution medium that was used 
was composed of $500 \mathrm{ml}$ phosphate buffer ( $\mathrm{pH}$ 6.6) and release was determined at $37 \pm 0.5^{\circ} \mathrm{C}$, at $50 \mathrm{rpm}$. A cyanoacrylate adhesive was used to attach the buccal tablet backing layer to the glass slide. And the slide was placed at the bottom of the vessel. At specific time intervals, various samples $(5 \mathrm{ml})$ were taken out of the medium and replaced with fresh content. Filter paper (Whatman filter paper) was used to filter the samples and appropriate dilution was prepared prior to spectrophotometric analysis (Pharmaspec-17, Shimadzu, Japan) at $238 \mathrm{~nm} .{ }^{21}$

\section{RESULTS AND DISCUSSION}

The solid dispersion of simvastatin was prepared to overcome the solubility problems associated with the drug. Dichloromethane solvent was selected for spray drying because of the limitation of outlet temperature below $35^{\circ} \mathrm{C}$. Various batches of solid dispersion were prepared for optimization. During initial batches of simvastatin: PVP (1:1) the product recovery was low because drugs formed usinga polymer carrier which is soluble in water results in atacky or sticky formation leading to a decreased recovery of solid dispersion and making the handling of the subsequent processes harder. To obtain free-flowing powder and to increase the yield, Aerosil 200 was added due to its anti-sticking properties. SD (1:2:2) and SD (1:3:2) was obtained as a free-flowing powder with a practical yield of $75 \%$ and 70\%, respectively. Further increase in PVP amount diminishes the powder characteristics of solid dispersion.

\section{Drug Content}

Table 4 shows the drug content of prepared solid dispersion. The drug content of SD (1:1) was observed to be low $(63 \pm 3 \%)$ which might be due to loss of drug during spray drying and stickiness of carrier. Drug content of SD (1:2:2) and SD (1:3:2) was found to be $76 \pm$ $2.37 \%$ and $87 \pm 1.23 \%$.

\section{Saturation Solubility}

Table 3 shows saturation solubility of prepared physical mixture and solid dispersion. Pure simvastatin has saturation solubility $16 \pm 0.77 \mu \mathrm{g} / \mathrm{ml}$. For SD (1:1) solubility was observed to be $47 \pm 1.08 \mu \mathrm{g} / \mathrm{ml}$. The saturation solubility was noticed to increase as the number of PVP increases. SD (1:2:2) and SD (1:3:2) have solubility $71 \pm$ $2.15 \mu \mathrm{g} / \mathrm{mL}$ and $85 \pm 2.49 \mu \mathrm{g} / \mathrm{ml}$, respectively.

\section{FTIR analysis}

To determine if there any interaction occurs between the excipients and drug FTIR spectroscopic analysis

Table 2: Composition of simvastatin buccal tablet.

\begin{tabular}{|c|c|c|c|c|c|c|}
\hline \multicolumn{7}{|c|}{ A. Composition of core layer } \\
\hline $\begin{array}{l}\text { Formulation } \\
\text { code }\end{array}$ & Drug & $\begin{array}{l}\text { Drug } \\
\text { equivalent } \\
\text { to }(\mathrm{mg})\end{array}$ & $\begin{array}{l}\text { Carbopol } \\
934(\mathrm{mg})\end{array}$ & $\begin{array}{c}\text { HPMC } \\
\mathrm{K} 4 \mathrm{M}(\mathrm{mg})\end{array}$ & $\begin{array}{c}\text { Mg. } \\
\text { Stearate } \\
\text { (mg) }\end{array}$ & $\begin{array}{c}\text { Total } \\
\text { weight } \\
\text { (mg) }\end{array}$ \\
\hline $\mathrm{F} 1$ & Pure SIM & 5 & 71.50 & 71.50 & 2.00 & 150 \\
\hline $\mathrm{F} 2$ & SD $(1: 1)$ & 5 & 71.50 & 71.50 & 2.00 & 150 \\
\hline F3 & $\operatorname{SD}(1: 2: 2)$ & 5 & 71.50 & 71.50 & 2.00 & 150 \\
\hline $\mathrm{F} 4$ & $\operatorname{SD}(1: 3: 2)$ & 5 & 71.50 & 71.50 & 2.00 & 150 \\
\hline F5 & Pure SIM & 5 & 47.66 & 95.34 & 2.00 & 150 \\
\hline F6 & $\mathrm{SD}(1: 1)$ & 5 & 47.66 & 95.34 & 2.00 & 150 \\
\hline $\mathrm{F} 7$ & SD $(1: 2: 2)$ & 5 & 47.66 & 95.34 & 2.00 & 150 \\
\hline F8 & SD $(1: 3: 2)$ & 5 & 47.66 & 95.34 & 2.00 & 150 \\
\hline F9 & Pure SIM & 5 & 95.34 & 47.66 & 2.00 & 150 \\
\hline F10 & SD $(1: 1)$ & 5 & 95.34 & 47.66 & 2.00 & 150 \\
\hline F11 & SD $(1: 2: 2)$ & 5 & 95.34 & 47.66 & 2.00 & 150 \\
\hline F12 & $\operatorname{SD}(1: 3: 2)$ & 5 & 95.34 & 47.66 & 2.00 & 150 \\
\hline \multicolumn{7}{|c|}{ B. Composition for backing layer } \\
\hline $\begin{array}{l}\text { Ethyl cellulose } \\
\qquad(\mathrm{mg})\end{array}$ & $\begin{array}{c}\text { Carbopol } 934 \\
(\mathrm{mg})\end{array}$ & $\begin{array}{l}\text { PVP K } 32 \\
\quad(\mathrm{mg})\end{array}$ & \multicolumn{2}{|c|}{$\begin{array}{l}\text { Sodium saccharin } \\
\text { (mg) }\end{array}$} & $\begin{array}{l}\text { Tartrazine } \\
\text { (mg) }\end{array}$ & $\begin{array}{c}\text { Total } \\
\text { weight } \\
\text { (mg) }\end{array}$ \\
\hline 22.50 & 6.25 & 18.75 & \multicolumn{2}{|c|}{2.5} & 0.05 & 50 \\
\hline
\end{tabular}


Table 3: Drug content and saturation solubility of pure drug, prepared physical mixture and solid Dispersion.

\begin{tabular}{|c|c|c|c|c|c|c|c|}
\hline & Pure & \multicolumn{3}{|c|}{ Physical mixture } & \multicolumn{3}{c|}{ Solid dispersion } \\
\cline { 3 - 7 } & simvastatin & $\mathbf{1 : 1}$ & $\mathbf{1 : 2 : 2}$ & $\mathbf{1 : 3 : 2}$ & $\mathbf{1 : 1}$ & $\mathbf{1 : 2 : 2}$ & $\mathbf{1 : 3 : 2}$ \\
\hline Drug content $(\%)$ & - & $58 \pm 0.82$ & $65 \pm 1.63$ & $70 \pm 2.14$ & $63 \pm 3.00$ & $76 \pm 2.37$ & $87 \pm 1.23$ \\
\hline $\begin{array}{c}\text { Saturation } \\
\text { solubility }(\mathrm{\mu g} / \mathrm{ml})\end{array}$ & $16 \pm 0.77$ & $21 \pm 1.15$ & $29 \pm 0.84$ & $38 \pm 1.77$ & $37 \pm 1.08$ & $61 \pm 2.15$ & $75 \pm 2.49$ \\
\hline
\end{tabular}

\begin{tabular}{|c|c|c|c|c|c|c|c|c|}
\hline $\begin{array}{l}\text { Formulation } \\
\text { Code }\end{array}$ & $\begin{array}{l}\text { Hardness } \\
\left(\mathrm{Kg} / \mathrm{cm}^{2}\right)\end{array}$ & $\begin{array}{c}\text { Friability } \\
(\%)\end{array}$ & $\begin{array}{c}\text { Average } \\
\text { weight (mg) }\end{array}$ & $\begin{array}{c}\text { Surface } \\
\text { pH }\end{array}$ & $\begin{array}{l}\text { Mucoadhesive } \\
\text { strength (gm) }\end{array}$ & $\begin{array}{c}\text { Drug } \\
\text { content } \\
(\%)\end{array}$ & $\begin{array}{c}\text { Swelling } \\
\text { index (\%) }\end{array}$ & $\begin{array}{l}\text { Disintegration } \\
\text { time (h) }\end{array}$ \\
\hline $\mathrm{F} 1$ & $6.40 \pm 0.69$ & $0.370 \pm 0.14$ & $200.00 \pm 1.73$ & $\begin{array}{c}6.36 \pm \\
0.05\end{array}$ & $23.67 \pm 1.52$ & $\begin{array}{c}91.59 \pm \\
1.46\end{array}$ & $72.72 \pm 1.81$ & $14.00 \pm 1.00$ \\
\hline $\mathrm{F} 2$ & $6.56 \pm 0.40$ & $0.374 \pm 0.15$ & $199.34 \pm 0.57$ & $\begin{array}{c}6.56 \pm \\
0.05\end{array}$ & $23.12 \pm 1.29$ & $\begin{array}{c}97.35 \pm \\
1.30\end{array}$ & $70.70 \pm 1.55$ & $14.00 \pm 0.50$ \\
\hline F3 & $5.83 \pm 0.35$ & $0.222 \pm 0.10$ & $200.34 \pm 0.57$ & $\begin{array}{c}6.43 \pm \\
0.23\end{array}$ & $21.33 \pm 0.57$ & $\begin{array}{c}98.17 \pm \\
0.88\end{array}$ & $73.13 \pm 1.92$ & $14.30 \pm 0.20$ \\
\hline $\mathrm{F} 4$ & $5.60 \pm 0.60$ & $0.344 \pm 0.17$ & $198.67 \pm 0.57$ & $\begin{array}{l}6.46 \pm \\
0.05\end{array}$ & $22.33 \pm 0.16$ & $\begin{array}{c}98.70 \pm \\
0.84\end{array}$ & $73.64 \pm 1.62$ & $13.00 \pm 1.00$ \\
\hline F5 & $6.13 \pm 0.61$ & $0.329 \pm 0.10$ & $199.34 \pm 1.52$ & $\begin{array}{c}6.56 \pm \\
0.28\end{array}$ & $19.33 \pm 0.51$ & $\begin{array}{c}96.17 \pm \\
1.86\end{array}$ & $66.45 \pm 2.56$ & $12.00 \pm 0.65$ \\
\hline F6 & $6.40 \pm 0.52$ & $0.359 \pm 0.09$ & $200.67 \pm 0.57$ & $\begin{array}{c}6.46 \pm \\
0.11\end{array}$ & $18.25 \pm 0.24$ & $\begin{array}{c}92.65 \pm \\
2.00\end{array}$ & $67.36 \pm 1.33$ & $12.00 \pm 0.50$ \\
\hline $\mathrm{F} 7$ & $6.26 \pm 0.11$ & $0.207 \pm 0.06$ & $200.00 \pm 1.73$ & $\begin{array}{c}6.66 \pm \\
0.25 \\
\end{array}$ & $18.77 \pm 2.13$ & $\begin{array}{c}93.55 \pm \\
2.49\end{array}$ & $66.12 \pm 0.81$ & $11.00 \pm 1.00$ \\
\hline F8 & $6.33 \pm 0.50$ & $0.316 \pm 0.14$ & $199.67 \pm 0.57$ & $\begin{array}{c}6.60 \pm \\
0.34\end{array}$ & $19.08 \pm 1.83$ & $\begin{array}{c}94.02 \pm \\
0.72\end{array}$ & $68.87 \pm 0.44$ & $12.50 \pm 0.50$ \\
\hline F9 & $5.80 \pm 0.20$ & $0.325 \pm 0.15$ & $199.00 \pm 1.00$ & $\begin{array}{c}6.36 \pm \\
0.23\end{array}$ & $27.67 \pm 0.57$ & $\begin{array}{c}93.10 \pm \\
1.97\end{array}$ & $82.14 \pm 1.37$ & $16.50 \pm 0.50$ \\
\hline F10 & $6.53 \pm 0.61$ & $0.364 \pm 0.14$ & $200.34 \pm 1.15$ & $\begin{array}{c}6.43 \pm \\
0.05\end{array}$ & $26.45 \pm 1.32$ & $\begin{array}{c}94.64 \pm \\
2.50\end{array}$ & $83.65 \pm 1.52$ & $15.00 \pm 0.24$ \\
\hline F11 & $6.20 \pm 0.60$ & $0.265 \pm 0.08$ & $200.34 \pm 1.15$ & $\begin{array}{l}6.23 \pm \\
0.05\end{array}$ & $26.85 \pm 0.89$ & $\begin{array}{c}95.06 \pm \\
2.16\end{array}$ & $82.37 \pm 0.84$ & $16.00 \pm 0.45$ \\
\hline F12 & $6.40 \pm 0.52$ & $0.285 \pm 0.10$ & $198.67 \pm 0.57$ & $\begin{array}{c}6.53 \pm \\
0.15\end{array}$ & $27.03 \pm 0.25$ & $\begin{array}{c}95.73 \pm \\
3.08\end{array}$ & $80.75 \pm 0.43$ & $15.00 \pm 0.30$ \\
\hline
\end{tabular}

Average of triplicate was reported. ( $\pm S D$ ).

was performed. Figure 1. Shows individual IR spectra for different formulations of simvastatin. The infrared spectra, in the case of pure drug, forms distinctive functional peaks (Figure 1a.) at 3546.51 (Free 0-H Stretch), 3010.82 (olefinic C-H stretch), 2969.1 (CH3 C - H symmetric stretching), 1701.8 (ester $\mathrm{C}=\mathrm{O}$ stretching), 1369.1 (Gem dimethyl C-H bend), 1269.0 (Lactone C-O-C stretching) and $1055.6 \mathrm{~cm}^{-1}$ (Secondary alcohol C-O stretch), while, in case of physical mixtures, characteristic peaks were observed at 2961.5, 1686.7, 1376.0, 1280.4, $1062.7 \mathrm{~cm}^{-1}$ with insignificant wave numbers shift. This tiny change might be due to the adsorbent used or due to the amorphous nature of polymers. There is a possibility that during the preparation of physical mixture (mixing and trituration of excipients and drugs for 10 min.) some functional group of drug and excipients may overlap and can form very weak hydrogen bonding which results into the negligible shift in wavelength. The presence of Aerosil 200 in the physical mixture and solid dispersion may influence the overall spectrum of the drug. Aerosil shows a characteristic prominent peak at $1115.08 \mathrm{~cm}^{-1}$. In the solid dispersion, there is no significant difference in individual spectra. The PVP and drug promote the hydrogen bonding interaction which is proved by a prominent peak at $1683 \mathrm{~cm}^{-1}$.

\section{XRD Analysis}

The X-Ray diffraction study is conducted to evaluate any change in the crystalline nature of pure drug by processing with or addition of other polymers. The XRD study of polymers, pure drug and physical mixture was carried out on X-Ray diffractometer (Figure 2.). Pure simvastatin during XRD studies was characterized by 


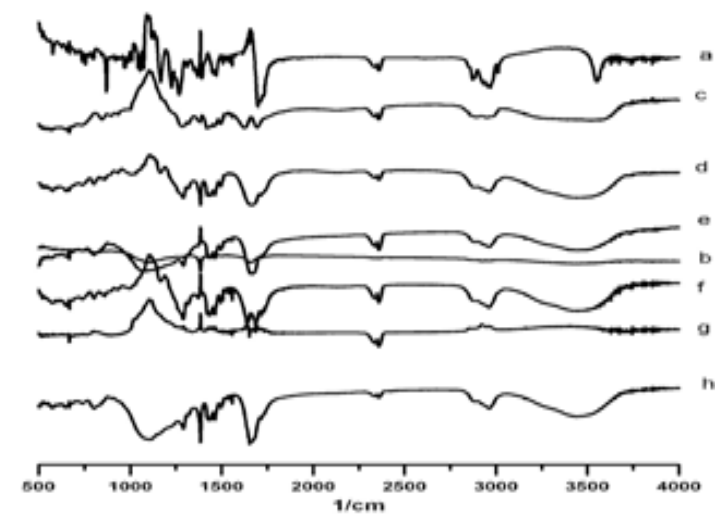

Figure 1: Infrared spectrum of different formulations of simvastatin. Key: (a) Pure simvastatin; (b) PVP; (c) PM 1:1; (d) PM 1:2:2; (e) PM 1:3:2; (f) SD 1:1; (g) SD 1:2:2; (h) SD 1:3:2.

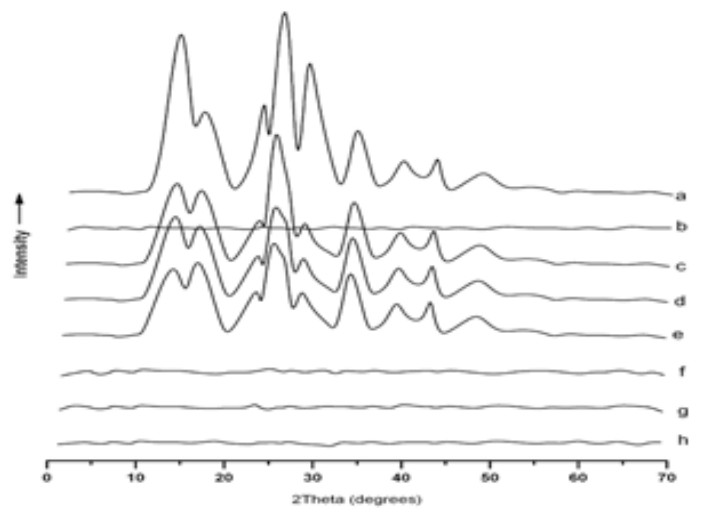

Figure 2: X-ray powder diffraction pattern of different formulations of simvastatin. Key: (a) pure simvastatin; (b) PVP; (c) PM 1:1; (d) PM 1:2:2; (e) PM 1:3:2; (f) SD 1:1; (g) SD 1:2:2; (h) SD 1:3:2.

prominent diffraction peaks (see Figure 2a.) within the range of 10-70 020. The characteristic peaks of simvastatin were observed at 14.005, 16.32, 25.75, 28.14, 32.03, 33.05 and $39.6602 \theta$. These peaks indicate the crystalline nature of simvastatin. The physical mixture shows diffraction peaks at 14.040, 25.800, 28.24, 33.06 and 39.09 020. A considerable drop in the intensity of some key simvastatin crystalline peaks was seen in diffractogram of physical mixture. The obtained results indicated that the partial loss in crystallinity of pure drug might be detected because of the physical occurrence of amorphous excipients. However, in solid dispersion, the traces of crystallinity not observed might be because of the presence of amorphous nature of Aerosil 200 or because the Aerosil 200 gets completely covered or adsorbed on the drug particulates.

\section{DSC Analysis}

To investigate the change in thermal properties of drug DSC analysis of simvastatin, physical mixture, polymers

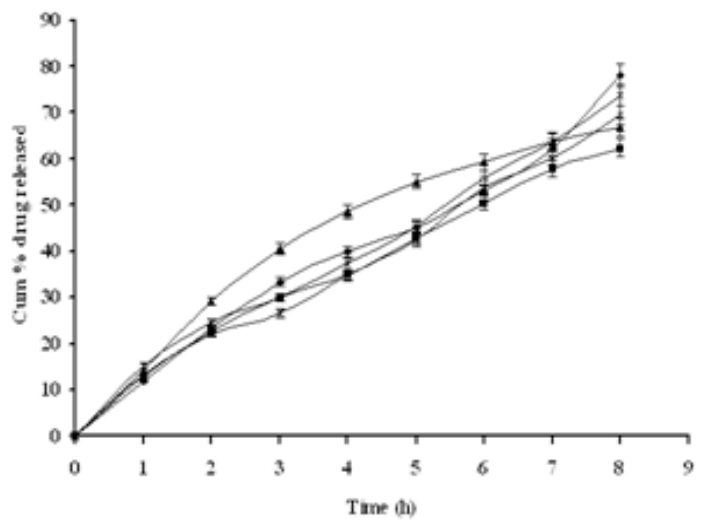

Figure 3: DSC thermograms of different formulations of simvastatin. Key: (a) pure simvastatin; (b) PVP; (c) PM 1:1; (d) PM 1:2:2; (e) PM 1:3:2; (f) SD 1:1; (g) SD 1:2:2; (h) SD 1:3:2.

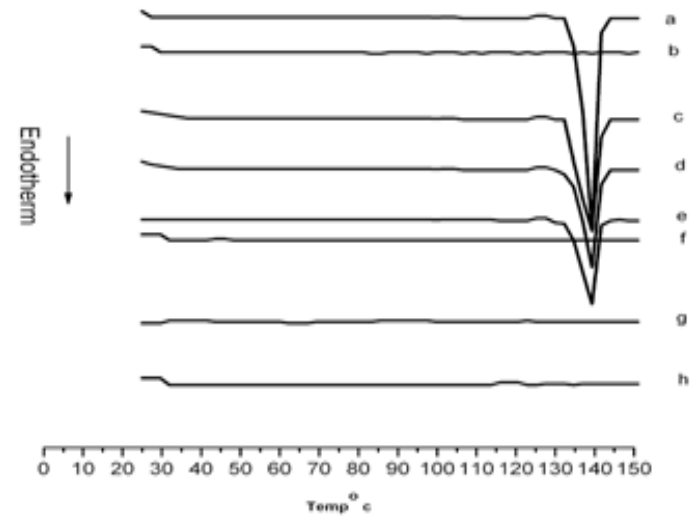

Figure 4: In vitro release profiles of different formulations of simvastatin. Key: ( $\bullet$ Pure simvastatin; (घ) simvastatin buccal tablet F9; ( $\triangle$ ) SD 1:1 buccal tablet F10; (x) SD 1:2:1 buccal tablet F11; (ж) SD 1:3:2 buccal tablet F12.

and solid dispersion were performed. The thermogram of simvastatin in pure form was a melting endotherm with sharp edge at $139.5^{\circ} \mathrm{C}$ (Figure 3a) while due to amorphous nature of polymers no endothermic peak appeared in case of polymers. In the case of a physical mixture (see Figure 3b), a graph with a peak at $134.56^{\circ} \mathrm{C}$ was obtained showing insignificant variation in endotherm due to the presence of residual crystallinity, where this slight variation in drug's melting temperature can be accredited to the addition of amorphous excipients with the increase in the quantity of PVP a straight line graph is formed without any endothermic transitions.

These results are also supported by diffractogram (Figure $2 \mathrm{~g}$ ) which showed the presence of amorphous nature of drug in spray-dried form.

\section{Tablet preparation and evaluation}

In this work, mucoadhesive polymers and antihyperlipidemic drug simvastatin were selected for the development of bucco-adhesive tablets. The selection was 
made based on the non-irritant, bio-adhesive nature and because of being safe and showing no irritancy. The purpose is to develop buccal tablets providing unidirectional drug release. In the core layer, the mixture of drug and mucoadhesive substance was incorporated (combinations of CP 934P: HPMC K4M) which interacts with the mucosal surface. A second upper backing layer then protects this core layer from the oral cavity environment. Due to the water impermeable nature of ethyl cellulose, it is selected as the backing layer compound. To avoid premature cracking CP 934P and PVP K32 (in a ratio of 1:3) were added to the backing layer. Sodium saccharin was added as a sweetening agent, while tartrazine is added as a coloring agent and to distinguish the two layers. The thickness of the formulations was found to be 2.01 to $2.02 \mathrm{~mm}$ respectively.

\section{Surface $\mathrm{pH}$ determination}

Table 4 shows the surface $\mathrm{pH}$ of all buccal tablets prepared. The bilayer tablets showed a surface $\mathrm{pH}$ between $6.23 \pm 0.05$ to $6.66 \pm 0.25$. The examination specify that the produced buccal tablets will be free from causing irritate risks to the mucosal surface.

\section{Swelling studies}

An essential property of a buccal adhesive system is appropriate swelling behavior. It ensures the extended and uniform release of drug and effective mucoadhesion. The hydration rate directly effects the swelling index of the drug, which is to say, an increase in swelling index can be taken as the weight of the tablet increases due to hydration. Table 4 shows the swelling index of the formulation F1-F12. The obtained results indicate that swelling indices of the prepared buccal tablets rises with the increasing amount of CP. Maximum swelling index obtained in buccal tablets contains CP: HPMC in the ratio of $2: 1$.

\section{Ex vivo mucoadhesive strength}

The adhesion between mucus and a polymer is defined as mucoadhesion. This adhesive force depends on various factors, for instance, the contact time with mucus, the molecular weight and polymer swelling rate and the biological membrane used in the study. The biological membrane for mucoadhesion studies used in the current study was the sheep buccal mucosa. Table 4 represents the obtained values of mucoadhesive strength for all formulations. The buccal tablet bio adhesive strength was observed to be in between $18.25 \pm 0.24$ to $27.66 \pm 0.57$

g. The highest bio adhesive strength of $27.67 \pm 0.57 \mathrm{~g}$ was displayed by the bilayered tablets containing $\mathrm{CP}$ and HPMC in 2:1 ratio (F9). Bilayered tablets showed good mucoadhesive strength with a higher proportion of $\mathrm{CP}$, which might be due to the presence of the polymer chains in the interfacial regions as compared to other polymers which only undergoes superficial bio-adhesion resulting in low bio-adhesive strength. The high adhesion may also be due mucin that might form secondary bio-adhesion bonds with it.

\section{Disintegration test}

The disintegration test can check the integrity of the formation of the buccal tablet. A buccal tablet immersed in water takes a bit of time to hydrate, as a result of which it starts swelling and eventually it slowly disintegrates. The time which the prepared buccal tablet takes to dissolve was noted to be in between $11.00 \pm 1.00$ to 16.50 $\pm 0.50 \mathrm{hr}$. Table 4 represents the disintegration time for all formulations. The achieved results indicated that due to the high viscosity and molecular weight of carbopol the disintegration time increases with the increase in carbopol.

\section{In vitro drug release study}

Figure 4 demonstrates the in-vitro drug release graph for selected formulations depending upon optimum swelling index, mucoadhesive strength and disintegration time. Pure simvastatin shows cumulative drug released $77.98 \%$ in $8 \mathrm{~h}$. Simvastatin formulated in a buccal tablet (F9) shows cumulative drug released $62.34 \%$ in $8 \mathrm{~h}$. This decrease in drug release is due to properties of mucoadhesive polymers which release the drug in a sustained/controlled manner. The spray dried simvastatin formulated in buccal tablet showed drug released $66.76 \%, 69.46 \%, 73.77 \%$ for formulation F10 (SD 1:1), F11 (SD 1:2:2) and F12 (SD 1:3:2) respectively in $8 \mathrm{hr}$. The obtained results suggested that an increase in the amount of PVP in solid dispersion would increase the drug release. This increase in drug release from spray dried formulation may be accredited to enhanced dissolution of drug particles due to the amorphous excipients presence and decreased crystallinity of drug. Increase in drug release from solid dispersion showed the presence of the drug in the amorphous state which is also confirmed by FTIR, XRD and DSC studies.

\section{CONCLUSION}

It can be concluded that to improve bioavailability, it is essential to enhance the dissolution and solubility characteristics of drugs which are poorly soluble. One of the approaches is the physical transformation of crystalline pills into amorphous nature. In this study, a solid dispersion of simvastatin was successfully achieved using the spray drying technique. FTIR, XRD and DSC studies did the confirmation of the presence of an amorphous 
form of simvastatin. The possibility of hydrogen bonding in solid dispersion was confirmed by IR studies and supported by XRD and DSC.

The simvastatin amorphous form as found in a powdered solid dispersion, explains better dissolution rate compared to solid dispersion tablets as analyzed by $\mathrm{X}$-ray diffraction. Use of solid dispersion form of simvastatin exhibited better results than the physical mixture. It showed better solubility, decreased crystallinity and improved dissolution rate. Dissolution studies from buccal tablet revealed the influence of polymers and amorphous nature of drug on the release of the drug. The current study thus establishes a potential application of the technique of spray drying to form solid dispersion of poorly water-soluble drug simvastatin.

\section{ACKNOWLEDGEMENT}

This research was supported by Deanship of Scientific Research, King Faisal University, Al-Ahsa, Kingdom of Saudi Arabia. (Grant Number: 180129).

\section{CONFLICT OF INTEREST}

The authors declare no conflict of interest.

\section{ABBREVIATIONS}

FTIR: Fourier Transform Infrared spectroscopy; XRD: X-ray diffraction; DSC: Differential scanning calorimetry; HPMC: Hydroxypropyl methylcellulose; GIT: Gastrointestinal Tract; FDA: Food and Drug Administration; PEG: Polyethylene Glycol; PVP: Polyvinylpyrrolidone; EC: Ethyl cellulose; UV: Visible Spectrophotometer; USP: United States Pharmacopoeia; ICH: International Conference on Harmonisation; SD: Solid Dispersion.

\section{REFERENCES}

1. Noyes AA, Whitney WR. The Rate of Solution of Solid Substances in their own Solutions. Journal Of The American Chemical Society. 1897;19(12):9304. DOI: $10.1021 / \mathrm{ja02086a003}$

2. Kaneniwa N, Ikekawa A, Hashimoto K. Influence of Operational Variables on Ball-Milling of Sulfadimethoxine and White Alundum. Chemical and Pharmaceutical Bulletin. 1973;21(3):676-81. DOI: 10.1248/cpb.21.676

3. Yamamoto $\mathrm{K}$, Nakano $\mathrm{M}$, Arita $\mathrm{T}$, et al. Dissolution rate and bioavailability of griseofulvin from a ground mixture with microcrystalline cellulose. J Pharmacokinet Biopharm. 1974;2(6):487-93. 1974/12/01
4. Kimura K, Hirayama F, Arima H, et al. Effects of Aging on Crystallization, Dissolution and Absorption Characteristics of Amorphous Tolbutamide2-Hydroxypropyl- and beta;-cyclodextrin Complex. Chemical and Pharmaceutical Bulletin. 2000;48(5):646-50. DOI: 10.1248/cpb.48.646

5. Pethe A, Salunkhe S, Premchandani T. Formulation and evaluation of mucoadhesive buccal tablet of simvastatin. Archives of Pharmacy Practice. 2012;3(1):27.

6. Alonso MJ, Maincent P, Garcia-Arias T, et al. A comparative biopharmaceutical study of fresh and ageing tolbutamide-polyethyleneglycols solid dispersions. International Journal of Pharmaceutics. 1988;42(1-3):27-33. DOI: https://doi. org/10.1016/0378-5173(88)90156-1

7. Arias MJ, Ginés JM, Moyano JR, et al. Influence of the preparation method of solid dispersions on their dissolution rate: Study of triamterene-d-mannitol system. International Journal of Pharmaceutics. 1995;123(1):25-31. DOI: https://doi.org/10.1016/0378-5173(95)00026-F

8. Kai T, Akiyama $\mathrm{Y}$, Nomura $\mathrm{S}$, et al. Oral absorption improvement of poorly soluble drug using solid dispersion technique. Chem Pharm Bull. 1996;44(3):568-71. 1996/03/01

9. Tambosi G, Coelho PF, Luciano $S$, et al. Challenges to improve the biopharmaceutical properties of poorly water-soluble drugs and the application of the solid dispersion technology. Matéria. 2018;23(4).

10. Chiou WL, Riegelman S. Preparation and dissolution characteristics of several fast-release solid dispersions of griseofulvin. J Pharm Sci. 1969;58(12):150510. $1969 / 12 / 01$

11. Simonelli AP, Mehta SC, Higuchi WI. Dissolution rates of high energy polyvinylpyrrolidone (PVP)-sulfathiazole coprecipitates. J Pharm Sci. 1969;58(5):538-49. 1969/05/01

12. Corrigan OI. Thermal analysis of spray dried products. Thermochimica Acta. 1995;248:245-58. DOI: https://doi.org/10.1016/0040-6031(94)01891-J

13. Babu NJ, Nangia A. Solubility Advantage of Amorphous Drugs and Pharmaceutical Cocrystals. Crystal Growth and Design. 2011;11(7):2662-79. DOI: $10.1021 / \mathrm{cg} 200492 \mathrm{w}$

14. DenMooter GV, Wuyts M, Blaton N, et al. Physical stabilisation of amorphous ketoconazole in solid dispersions with polyvinylpyrrolidone K25. Eur J Pharm Sci. 2001;12(3):261-9. 2000/12/13

15. Serajuddin AT. Solid dispersion of poorly water-soluble drugs: Early promises, subsequent problems and recent breakthroughs. J Pharm Sci. 1999;88(10):1058-66. 1999/10/09

16. Hancock BC, Zografi G. The Relationship Between the Glass Transition Temperature and the Water Content of Amorphous Pharmaceutical Solids. Pharmaceutical Research. 1994;11(4):471-7. journal article. DOI: 10.1023/a:1018941810744

17. Yoshioka M, Hancock BC, Zografi G. Crystallization of indomethacin from the amorphous state below and above its glass transition temperature. J Pharm Sci. 1994;83(12):1700-5. 1994/12/01

18. Leuner C, Dressman J. Improving drug solubility for oral delivery using solid dispersions. Eur J Pharm Biopharm. 2000;50(1):47-60. 2000/06/07

19. Ford $\mathrm{JL}$, Rubinstein $\mathrm{MH}$. Formulation and ageing of tablets prepared from indomethacin-polyethylene glycol 6000 solid dispersions. Pharm Acta Helv. 1980;55(1):1-7. 1980/01/01

20. Nakhat PD, Kondawar AA, Rathi LG, et al. Development and in vitro evaluation of buccoadhesive tablets of metoprolol tartrate. Indian Journal of Pharmaceutical Sciences. 2008;70(1):121-4. DOI: 10.4103/0250-474X.40349

21. Patel AR, Vavia PR. Preparation and in vivo evaluation of SMEDDS (selfmicroemulsifying drug delivery system) containing fenofibrate. The AAPS journal. 2007;9:E344-E352. DOI: 10.1208/aapsj0903041

22. Mumtaz AM, Ch'ng HS. Design of a dissolution apparatus suitable for in situ release study of triamcinolone acetonide from bioadhesive buccal tablets. International Journal of Pharmaceutics. 1995;121(2):129-39. DOI: https://doi. org/10.1016/0378-5173(94)00406-U 


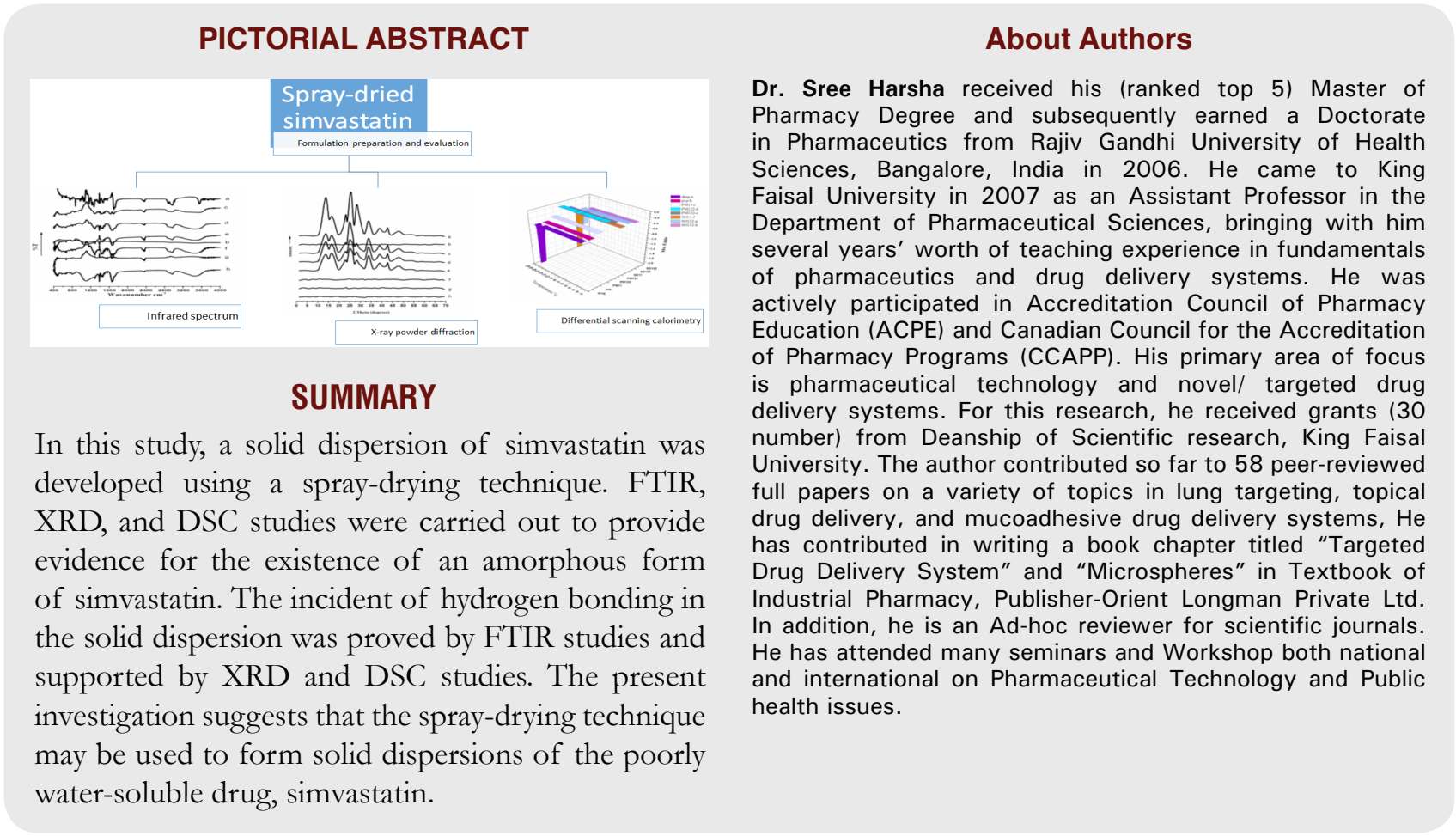

Cite this article: Sree Harsha N, Hiremath JG, Sarudkar S, Attimarad M, Al-Dhubiab BE, Nair AB, Venugopala KN, $\mathrm{AH}$ Asif. Spray Dried Amorphous form of Simvastatin: Preparation and Evaluation of the Buccal Tablet. Indian $\mathrm{J}$ of Pharmaceutical Education and Research. 2020;54(1):46-54. 